Amaltea. Revista de mitocrítica

ISSN-e: 1989-1709

http://dx.doi.org/10.5209/AMAL.58785

\title{
«El libro en blanco» de Julio Ramón Ribeyro: el motivo del libro asesino
}

\author{
Gustavo Alberto Quichiz Campos ${ }^{1}$
}

Recibido: 1 de febrero de 2018 / Aceptado: 25 de mayo de 2018

Resumen. Este trabajo analiza una de las claves de verosimilitud más frecuentes en el cuento fantástico: el objeto mágico, específicamente, en el motivo del libro asesino. Se presenta un resumen del motivo desde los mitos, pasando por la literatura caballeresca, hasta la actualidad. También se analiza «El libro en blanco» de Julio Ramón Ribeyro, un cuento donde el autor concibe un libro que solo trae la desgracia a sus poseedores y cuya principal innovación es la capacidad de ser el agente de su propia perversidad. Lo metaliterario del relato hace inevitable su análisis en relación con la creación novelística en Ribeyro. Palabras clave: Julio Ramón Ribeyro, El libro en blanco, objeto mágico, libro asesino, metaliteratura, mito, magia.

\section{[en] «El libro en blanco» by Julio Ramón Ribeyro: the motif of the killer book}

\begin{abstract}
This work analyzes one of the more frequent keys of plausibility in a fantastic story: the magic object, specifically, in the motif of the killer book. It's presented a recap of the motif from the myths, passing through chivalric literature, until the present day. It is also analyzed «El libro en blanco» by Julio Ramón Ribeyro, a story that presents us a book that only brings misfortunes to its possessors and whose main innovation is the book's capacity of being the agent of its own perversity. The metaliterary of the story makes its analysis inevitable in relation to the novelistic creation in Ribeyro.
\end{abstract}

Keywords: Julio Ramón Ribeyro, El libro en blanco, fantastic, magic object, killer book, metaliterature, myth, magic.

Sumario. 1. Introducción. 2. Asesinos sigilosos. 3. El libro asesino de Julio Ramón Ribeyro. 4. Conclusiones. 5. Obras citadas.

Cómo citar: Quichiz Campos, G. A. (2018). «El libro en blanco» de Julio Ramón Ribeyro: el motivo del libro asesino. Amaltea. Revista de mitocrítica 10, 2018, 67-78.

\section{Introducción}

En 1945, en su discurso ante la Sociedad Argentina de Escritores tras haber recibido el Gran Premio de Honor por Ficciones, Borges definió lo fantástico como «el género más antiguo, [...] [pues,] bajo cualquier latitud, la cosmogonía y la mitología son anteriores a la novela de costumbres» (ctd. en Rodríguez, E. 449). Como él, muchos

\footnotetext{
$1 \quad$ Universidad de Zaragoza gaquichizc@gmail.com https://ieiop.academia.edu/GustavoQuichizCampos.
} 
otros autores ubican la aparición de lo fantástico junto al mito por presentar un hecho sobrenatural. Es, sin embargo, a partir del último tercio del siglo XX, con la aparición de trabajos imprescindibles en el estudio de lo fantástico, como los de Tzvetan Todorov e Irene Bessière, que se empiezan a marcar las diferencias entre estos géneros no miméticos o no realistas y se reconoce que la delimitación de lo real en lo fantástico aparece de forma más acusada que en la mitología o lo maravilloso.

En Tras los límites de lo real (2011), David Roas señala que mientras podemos referirnos a gran parte de la literatura fantástica del siglo XIX como hija de las teorías newtonianas, la del siglo XX es una reacción a la mecánica cuántica, donde, rotas las nociones del espacio y tiempo, la percepción de la realidad se vuelve relativa al individuo, de modo que si bien en apariencia los primeros relatos fantásticos se caracterizaron por la simple «afirmación de lo sobrenatural [...] [lo fantástico moderno se orienta en cambio a] la deconstrucción de lo real, al cuestionamiento de su consistencia» (Martínez, Fantasías 407). Habría que entender lo fantástico, por lo tanto, no como «un género particular dentro de la literatura y sí, por el contrario, [como] un síntoma o expresión que define una modalidad de narrar» (Belevan XLVIII), la cual «refleja, bajo el aparente juego de la invención pura, las metamorfosis culturales de la razón y del imaginario colectivo» (Bessière 184).

En este sentido, y si bien puede compartir la presencia de lo sobrenatural como la mitología o lo maravilloso, «lo fantástico exige una condición más: la transgresión de las leyes del mundo real objetivo» (Rodríguez, J. 147), es decir que

para que el texto fantástico se produzca, el mundo construido en el interior del texto siempre ofrece signos que puedan ser interpretados a partir de la experiencia del mundo que tiene el lector. Esto le permite contrastar las opuestas naturalezas de los acontecimientos narrados y captar su relación conflictiva. (Roas 48)

Estamos, por lo tanto, frente a dos órdenes ontológicos en fricción: por un lado, el mimético o realista (el mundo normal u ordinario), que «puede ser vertido en un lenguaje igualmente mimético y transparente»; y, por el otro, todo aquello que supone «un desafío constante para los afanes del conocimiento sensible y la razón lógica» (Martínez, Subversión 363). Y, tal vez porque la crítica fantástica se ha enfocado mayormente en estudios sobre esta segunda dimensión, aún hoy no hay estudios preponderantes sobre, paradójicamente, «uno de los recursos de verosimilitud más frecuentes en el relato fantástico» (Martínez, Subversión 364): el objeto mágico.

Sea fantástico clásico o moderno, la importancia del objeto mágico para la narrativa fantástica ya solo puede acotarse en la cantidad de relatos a los que ponen nombre. No se les debe confundir, sin embargo, con el maravilloso instrumental que menciona Todorov, pues, al contrario de estos objetos «producidos por la habilidad humana [...], [existen otros que son] semejantes en apariencia, pero cuyo origen es mágico» (Todorov 80). Presentados en medio de un aura de misterio y vaguedad, los objetos mágicos suelen pasar a tener una importancia menor en el relato después de la focalización narrativa al inicio del cuento, cuando, ocultos bajo el disfraz perfecto de su aparente condición natural, la descripción de su aspecto físico dota al texto de verosimilitud.

Sin ningún afán de establecer una tipología, en algunos de estos relatos el talismán en particular otorga placeres o cualidades a su poseedor con muy distinta fortu- 
na, como puede verse en La peau de chagrin (1831) de Honoré de Balzac, que otorga beneficios a su dueño a cambio de ir acortando su vida, o «The Monkey's Paw» (1902) de W. W. Jacobs, donde la posibilidad de ver sus deseos cumplidos se vuelve en contra de una familia; en otros relatos, en cambio, su presencia justifica la veracidad de la anécdota fantástica, teñida por la vigilia o la fiebre, como ocurre en «Le pied de momie» (1840) de Théophile Gautier o la breve nota de Coleridge que Borges citara en su artículo «La flor de Coleridge»: «Si un hombre atravesara el Paraíso en un sueño, y le dieran una flor como prueba de que había estado allí, y si al despertar encontrara esa flor en su mano... ¿entonces, qué?» (639).

Sin embargo, hay otros relatos que apuntan a una desgracia acaecida por el poder de estos objetos en sí mismos, como sucede en «El Zahir» (1949) de Borges, donde el persistente recuerdo de una moneda lleva al protagonista a la locura, o, precisamente, en el cuento que ahora nos ocupa: «El libro en blanco» de Julio Ramón Ribeyro (1929-1994).

Asociado sobre todo a una narrativa realista que con crudeza refleja la situación de los marginados de la sociedad peruana, el estilo de Ribeyro se caracteriza por eludir casi cualquier tipo de experimentalismo -Vargas Llosa decía de él que «la transparencia de su estilo es engañosa» (264)-. Pese a ello, su concepción de lo fantástico estaba ligada a los autores hispanoamericanos del siglo XX, llegando a señalar que: «En parte comparto la teoría de Cortázar de que lo "mágico" está en lo cotidiano, en nuestra realidad» (Ribeyro, Respuestas 225).

Con todo, la vertiente fantástica de este escritor peruano ha estado siempre a la sombra de la atención que tanto la crítica como el público han enfocado en la dimensión realista de su obra. La razón más evidente de este hecho tal vez se encuentre en las escasas incursiones del autor en lo fantástico, cuyo corpus de relatos hoy día aún dista de estar cerrado ${ }^{2}$ y apenas sobrepasa la decena de los noventa y cinco que componen toda su cuentística. ${ }^{3}$ Sin embargo, pese a este ejercicio intermitente, Ribeyro empieza y, de cierta manera, termina escribiendo cuentos fantásticos, ya que, junto a «La molicie» y «Nuit caprense cirius illuminata», también de cariz fantástico, «El libro en blanco» es uno de los últimos relatos que Ribeyro publicara en vida.

En «El libro en blanco», Ribeyro nos presenta un volumen maldito que actúa bajo su propia voluntad y cuya sola cercanía trae consigo la desgracia a sus poseedores, ocasionando que estos se arruinen, enfermen o incluso mueran. No obstante, antes de pasar al análisis del texto, me adentraré en una breve revisión del motivo del libro asesino, inevitablemente ligado al del libro mágico -y, por ende, a la magia-, desde su aparición en el mito hasta sus revisiones en la actualidad.

\section{Asesinos sigilosos}

El libro mágico aparece en numerosos mitos y leyendas, pasando por las aventuras caballerescas, hasta llegar a la actualidad. En su Motif-Index of Folk-Literature

2 Como ejemplo puede verse las diferentes selecciones propuestas por Vidal (81), Minardi (74), Martínez (Taxonomías 261) o Rodero (23).

3 Se incluyen los seis que publicó en revistas y diarios peruanos y que, junto al inédito «Surf» (1994), aparecen publicados en la última edición de La palabra del mudo (2009), volumen que recoge toda su narrativa breve. 
(1932), Stith Thompson recopila variantes del motivo del libro mágico (D1266. ${ }^{4}$ ) que, en su gran mayoría, proporcionan algún tipo de bien. Así, conceden salud (D1500.1.22.), riqueza (D1469.6.), consejo (D1312.4.), deseos (D1470.1.26.), controlan enfermedades (D1500.01.), adivinan el futuro (D1311.14.) o el destino (D1325.1.). Más fantástico aún -si acaso es posible hablar de una jerarquía de lo sobrenatural en este campo- son aquellos que hacen aparecer caminos (D1484.2.), secarríos (D1542.3.2.), dispersar demonios(D1385.25.), invocar genios(D1421.1.3.), defenderse de fantasmas (E434.8.) o resucitar a los muertos (E64.7.) Finalmente, otras anotaciones hablan de las cualidades mágicas de estos libros, como la capacidad de volver por sí mismos a sus dueños (D1602.10.) de ser incombustibles (D1656.1.), así como aquellos que dan su poder a las brujas (G224.3.) u hombres lobo (D113.1.1.).

De todos estos apuntes, sin embargo, el que más llama la atención es un motivo que desarrolla la idea de un «libro mágico que, una vez usado, obliga a la persona a hacer el mal» ${ }^{5}$ (D1678.). Al contrario que en el resto de motivos antes mencionados, en esta ocasión el libro mágico actúa como agente de su propio poder al poseer a la persona que lo utiliza. Thompson atribuye el origen del motivo al Cyprianus, libro de magia negra de origen nórdico que «begins by expaling what sorcery is, and with a warning against it. [...] In this book are taught exorcising, laying and raising of spirits» (Thorpe 187). Con todo, ya es llamativa que la idea del libro, que a lo largo de la historia y hasta el día de hoy está ligado al poder, sobrepase su cualidad de objeto y adquiera la de agente de su propio accionar, de manera similar a lo que veremos en «El libro en blanco».

En la introducción a la Antología de la literatura fantástica editada junto a Jorge Luis Borges y Silvina Ocampo, Adolfo Bioy Casares señala que «viejas como el miedo, las ficciones fantásticas son anteriores a las letras» y que, tal vez, «los primeros especialistas en el género fueron los chinos» (9). Uno de los relatos que componen dicha antología es precisamente un mito chino, «La protección del libro», documentado por Gerald Willoughby-Meade y publicado originalmente en 1928 como «Saved by the book» en la colección Chinese Ghouls and Goblins. En este relato, $\mathrm{Wu}$, un literato que había insultado a un mago llamado Chang Ch' Shen, pasa la noche leyendo el Libro de las Transformaciones,${ }^{6}$ seguro de que el mago procuraría vengarse. Durante la noche es atacado tres veces y las tres veces se defiende con el libro como arma. En todos los casos, tras ser golpeados por el libro, los atacantes son convertidos en figuras de papel. Al final del relato, las almas de los hombres que no han podido volver a su cuerpo, tras ser encerradas en estas figuras de papel, mueren,

$4 \quad$ D1266 es el número que Thompson da a este motivo y que indexa a su vez otros relacionados en mayor o menor medida que paso a listar a continuación. En todo caso, adjunto al lado de cada motivo específico su propio índice distintivo. Sin embargo, en muchas de estas anotaciones se puede observar que se intercambia libro mágico por libro sagrado (o evangelios), así como se le vincula con nociones como la escritura, los conjuros y las runas. Para este trabajo, solo he querido abarcar el concepto de libro para establecer una analogía con el relato que analizo y no referirme a la escritura al ser un fenómeno completamente distinto.

«Magic book, once used, compels person to do evil» en el inglés original.

6 O El libro de los cambios, es el I Ching, un libro chino que se utiliza para predecir el futuro; su concepción, asimismo, está ligada a la toma correcta de códigos de conducta moral, por lo que también tiene lecturas filosóficas. Aparece en la novela de ciencia ficción The Man on the High Castle (1962) de Philip K. Dick. En esta novela, el libro «is the device that, literally and figurativelly, unifies the stylistic and philosophical dimensions of the novel, leaving us with a sophisticated postmodern fiction that explores the boundaries of text and world, their overlappings and multiplicities» (Mountfort 287). 
de modo que, si ya a través de Thompson encontrábamos la primera mención a un libro con sus propias intenciones, aquí, aparentemente, estamos frente a la primera versión del motivo del libro asesino, cuya tradición, como veremos pronto, llega hasta la fecha.

En la literatura caballeresca, por otra parte, en «el férreo entrechocar de las armas [...], el arma absoluta es el libro mágico» (Calvino 119). Si bien su uso estaba mayormente restringido a los magos, cuyos poderes «[estaban] habitualmente del lado del mal, pero su magia nefasta podía transformarse en una ayuda provisional si caía en las manos adecuadas» (Calvino 118), el libro mágico era «empleado básicamente para producir el desencantamiento del héroe o protegerlo» (Nasif 788), como ocurre en el Amadís de Gaula (1508), en donde el héroe vuelve a la vida por medio de la lectura de un conjuro mágico de la maga Urganda, o en Orlando furioso (1532), donde Astolfo supera las estratagemas del mago Atlante gracias a su conocimiento mágico.

En las aventuras caballerescas ya se puede observar la importancia (y el respeto) al papel del libro en la sociedad. Así, los magos eran también llamados sabios. Se puede incluso decir que con estas narraciones se inicia «un proceso de legitimación de la magia» (Nasif 779), pues el

poder de un libro, y en especial el aura de misterio que rodea a un libro de magia, se expresa en numerosos escritos. Los manuscritos mágicos empleaban frecuentemente escritura cifrada con la que se procuraba, por un lado, el misterio y por otro, la protección de los saberes de los charlatanes. (Nasif 779)

Si bien actualmente las nociones de magia y libro se han ido desligando, todavía persisten ejemplos de libros con poderes mágicos y, sobre todo, asesinos. Así, en 1962, Julio Cortázar, en uno de los microcuentos que componen «Instruccionesejemplos sobre la forma de tener miedo» de Historias de cronopios y de famas, nos habla sobre algunos de estos peculiares volúmenes: «En un pueblo de Escocia venden libros con una página en blanco perdida en algún lugar del volumen. Si un lector desemboca en esa página al dar las tres de la tarde, muere» (17). Quince años después, se publica La asesina ilustrada de Enrique Vila-Matas, novela donde todas las personas que han leído el manuscrito epónimo terminan muertas. Finalmente, en 1980, aparece El nombre de la Rosa de Umberto Eco, donde, al contrario de la novela anterior, esta vez son las páginas impregnadas de veneno las culpables de una serie de muertes en la obra.

Una de las referencias más actuales aparece en Japón en el 2003, si bien dentro del ámbito del manga, con Death Note de Tsugumi Ohba, cuyo argumento gira alrededor de un cuaderno con la capacidad de matar a las personas cuyos nombres han sido escritos en él. No obstante, y aunque el autor no ha afirmado que ha sido fuente de inspiración, hay un antecedente directo en el mismo registro del cómic japonés, pues el motivo del libro asesino ya aparecía en Fushigi na Techou (El maravilloso cuaderno en español) de Shigeru Mizuki, publicado en 1973 y donde el poder del libro era exactamente el mismo que el creado por Ohba.

En general, se puede observar que el libro mágico es un motivo que aparece en la mayoría de estas historias como un instrumento sobrenatural, un objeto al servicio del hombre cuyo poder está a su disposición, ligado a la magia durante un tiempo, pero sobre todo establecido como un tópico más de los objetos mágicos que abundan 
en la narrativa fantástica. Es en este ámbito donde se enmarca «El libro en blanco» de Julio Ramón Ribeyro, cuya principal innovación es la capacidad del objeto de ejecutar su perversidad por sí mismo.

\section{EI libro asesino de Julio Ramón Ribeyro}

Escrito en octubre de 1993, «El libro en blanco» fue incluido en la colección Cuentos de circunstancias - publicada originalmente en 1958-como parte de los cambios que Ribeyro hizo para la segunda edición de La palabra del mudo de 1994. El relato, que mezcla lo fantástico con el humor a través de la ironía y lo metaliterario, nos presenta un libro florentino del siglo XVIII que llama la atención del narrador no solo por su encuadernación, sino por la calidad de sus páginas:

En las estanterías [...] vi el lomo de un libro forrado en damasco y sin ninguna referencia. Al sacarlo noté que todas sus páginas estaban en blanco. Pero era un hermoso libro, no solo por la encuadernación sino por la calidad del papel, que era grueso, ligeramente estriado y sus bordes exteriores bañados en pan de oro. (Ribeyro, Palabra 147)

Se puede observar que se cumplen las condiciones que abordan el motivo del objeto mágico en la literatura fantástica, pues, tras una presentación donde vagamente se sugiere un origen misterioso ante la falta de referencias o su condición inmaculada, la detenida descripción de su aspecto sirve para dotar al objeto de una completa verosimilitud, la misma que posibilita su traslado sigiloso a un segundo plano a medida que transcurre el relato, ya que su condición de libro maldito solo será revelada al final del mismo, cuando «la evidencia fáctica del enigma, [... a la vez clímax y conclusión[,] no ofrece espacio textual para cuestionar su [fantástica] realidad» (Martínez, Taxonomías 263).

«Es como para escribir allí una obra maestra» (Ribeyro, Palabra 147), dice en voz alta el protagonista al verlo por primera vez. Este innominado protagonista y narrador del cuento es un peruano en París que trabaja de traductor en una agencia de noticias, coleccionista aficionado de libros raros y antiguos, pero, sobre todo, un escritor que nunca escribe. El libro llega a sus manos como el inocente regalo de Francesa, una amiga a quien no veía hace mucho tiempo y que en los últimos años ha pasado de vivir en una linda y amplia casa en Versalles a un departamento pequeño en el bulevar de Saint-Germain. Además, ahora está divorciada y su trabajo, el comercio del arte, pasa por una época difícil. A ella a su vez el libro le fue regalado por su hermano, un anticuario que se lo dio al tener que liquidar su negocio -y que siempre odió que esta se hubiera casado con un peruano-. Solo tras volver a releer el relato caeremos en cuenta que la desgracia de ambos hermanos estaba ligada a la posesión de dicho volumen.

Desde que pasa a ser el nuevo dueño del libro en blanco, la vida del narrador empieza a torcerse, irónicamente, por culpa de la literatura. En primer lugar, tras encontrarlo leyendo En busca del tiempo perdido, su nuevo jefe lo castiga pasándolo al turno de la noche. Esto, a la larga, le termina por reactivar una vieja úlcera que lo lleva al hospital. Tiempo después, ya recuperado y de nuevo en el trabajo, el jefe vuelve a encontrarlo leyendo -esta vez Elogio de la pereza de Bertrand Russell-, y, 
tomándolo ahora como una afrenta personal, comienza un hostigamiento contra el protagonista que decide renunciar.

Este tono irónico, que acompaña todo el relato, permite observar que, en «El libro en blanco», tanto la ironía como lo metaliterario dotan de una insospechada profundidad al tópico del objeto mágico, ya que es a partir de estas hibridaciones con lo fantástico -características consolidadas y definitorias del fantástico actual o posmoderno-, como el relato de Ribeyro se convierte en uno de los primeros ejemplos de «motivos que tratados a la manera tradicional resultarían desfasados o demasiado vistos (y, por ello, previsibles), son renovados gracias al tratamiento irónico y/o paródico» (Roas, Álvarez y García 210).

Los pocos críticos que han trabajado este relato encuentran que Ribeyro vuelve fantástico el miedo del escritor a la página en blanco. González Montes, por ejemplo, propone un análisis similar al encontrar en el volumen maldito «una metáfora de la esterilidad de un escritor que no es capaz de romper el maleficio de la página en blanco y renuncia a explotar la capacidad creativa de la escritura» (48). Ewald Weitzdörfer, por su parte, observa que la posibilidad de escribir un libro y no hacerlo «es como tener un libro en blanco. El rechazo de un don natural es una violación de la naturaleza. Al igual que un libro sin contenido, un libro en blanco constituye una violación de la esencia de un libro, dos tipos de desnaturalización que merecen el castigo correspondiente» (196, énfasis suyo).

Pierre Vandoorne, por otro lado, hace el análisis del cuento en relación con «El libro de arena» (1975) de Borges, y encuentra que en ambos relatos «la simple posesión del libro resulta en la desgracia del dueño quien se ve obligado a deshacerse del objeto sin atreverse a destruirlo» (144). También llama la atención sobre «la imagen negativa del infinito» en el cuento de Ribeyro, pues, al estar en blanco, el libro no presenta principio ni final y, por lo tanto, es infinito como el de Borges. De modo que mientras lo fantástico en el cuento del argentino parte de la base de que un libro -un elemento finito- contenía lo infinito, el de Ribeyro encierra, a su manera, la promesa de todas las posibles historias, incluso la de una obra maestra -como afirma el mismo protagonista de la historia-, pero también -paradoja fantástica- puede no contener ninguna.

Con todo, la búsqueda de la plenitud artística en Ribeyro - un autor que nunca fue «invitado al festín del boom latinoamericano» (Esteban 142) y cuyo mayor reconocimiento, el premio «Juan Rulfo», coincidió con su muerte- es otra de las posibles lecturas que se pueden proponer para este texto:

Todos o casi todos los escritores de mi generación han escrito su gran libro narrativo, que condensa su saber, su experiencia, su técnica, su concepción del mundo y la literatura. [...] Sólo yo no he producido un libro equivalente y a los 48 años no creo que lo pueda producir. La obra vasta y compleja, densa y sinfónica, está fuera de mis posibilidades». (Ribeyro, Tentación 583; 28/10/1977)

Esta cacería infructuosa en busca de la gran novela ha sido ya explorada por el autor de manera simbólica en «Silvio en El Rosedal» (1977) y más explícitamente, aunque con diferentes resultados, en «Ausente por tiempo indefinido» (1987) y «Surf» (1994). En el primero de ellos, Silvio Lombardi recibe como herencia El Rosedal, una hacienda cuyo principal atractivo era un hermoso jardín en el que, por la disposición de los macizos de rosas, el protagonista de la historia cree vislumbrar 
un mensaje. La obsesión por descifrar el secreto del jardín lleva a Silvio a un estado de completo abatimiento, del que, sin embargo, resurge cuando reconoce «que la vida no necesita tener un sentido para ser soportable y hasta para proporcionar satisfacción» (Higgins 167):

Silvio trató otra vez de distinguir los viejos signos, pero no veía sino confusión y desorden, un caprichoso arabesco de tintes, líneas y corolas. En ese jardín no había enigma ni misiva, ni en su vida tampoco [...]. [Y] se sintió tranquilo, soberano [...]. Levantando su violín lo encajó contra su mandíbula y empezó a tocar para nadie, en medio del estruendo. Para nadie. Y tuvo la certeza de que nunca lo había hecho mejor (Ribeyro, Palabra 671)

Como el propio Ribeyro reconocería luego, el relato permite una lectura en la que podemos reconocer al propio autor encarnado en la figura de Silvio, ignorado por el gran público y condenado por su estilo a no hacer otra cosa «que seguir tocando el violín, es decir escribiendo, aunque nadie escuche la música por la vacarme y se pierda en las galaxias infinitas» (Ribeyro, Cartas 274).

Por su parte, en «Ausente por tiempo indefinido», Ribeyro nos presenta a Mario, un escritor peruano que no ha escrito nada después de un celebrado libro juvenil y que viaja a Chosica, al norte de Lima, buscando poder escribir al fin la novela que le quite el calificativo de promesa de la literatura y termine con su bloque literario, pues no había podido volver a escribir nada «aparte de la primera página de una novela [...]. Esa página admonitiva, acusatoria, era la prueba de su infecundidad, el testigo de su disipación, pero sobre todo la causa de su conciencia dolorosa» (Ribeyro, $\mathrm{Pa}$ labra 793). Tras una serie de imprevistos, al final del cuento, Mario ha conseguido terminar su novela, pero acabar el libro no ha significado la ansiada victoria artística, ya que tras su lectura se encuentra ante una novela fallida, sentimiento que Ribeyro ha revelado tener sobre su propia producción novelística.

«Surf», en cambio, es un relato de carácter marcadamente autobiográfico. El protagonista del cuento, Bernardo, es un escritor que se ha instalado-como hiciera él en sus últimos años de vida- en una casa en Lima frente al mar de Barranco, en «el espacio soñado, buscado y al fin encontrado donde, al bordear la sesentena, pensaba concluir apaciblemente su vida, escribiendo el libro que era indispensable para que su obra [...] alcanzara el reconocimiento unánime que, a su juicio, merecía» (Ribeyro, Palabra 1021). Al estilo de «Silvio en El Rosedal», el final del cuento tiene un sentido catártico para Ribeyro, ya que Bernardo, al observar por su ventana a jóvenes surfistas alzarse sobre las olas, empieza a practicar también el surf y, en las últimas líneas del cuento, erguido sobre su tabla, «sintió que la ola lo depositaba en su cresta y pronto se dio cuenta, en medio de una indecible felicidad, de que esa ola lo conducía sin perder el equilibrio, cada vez más aceleradamente, bajo una luz lunar que iluminaba los arrecifes, hacia la eternidad» (Ribeyro, Palabra 1028).

En «El libro en blanco», sin embargo, esta persecución toma un giro irónico cuando el narrador, un escritor que nunca escribe, amigo de otros escritores tan desvalidos como él, que solo se reunían «para beber vino barato, compartir nuestras desventuras e ilusionarnos con las obras maestras que esperábamos escribir» (Ribeyro, Palabra 149), sobrevive; mientras que el poeta Chocano, el «único que tenía realmente talento y gozaba de mejor situación» (Ribeyro, Palabra 149), muere al sí escribir. 
Al igual que el narrador, Álvaro Chocano queda fascinado por la belleza y rareza del ejemplar, por lo que el protagonista decide regalárselo: «Para que escribas tus mejores poemas» (Ribeyro, Palabra 149), le dice. Esta frase, junto a la ya antes mencionada («Es como para escribir allí una obra maestra»), son las únicas que se cruzan a partir de dicho ejemplar y, de cierta manera, avalan un análisis de la figura del libro en blanco ligada a la novela como excelencia narrativa para Ribeyro. Al contrario del narrador, Chocano sí escribe en el libro en blanco, lo que ya contradice las propuestas de análisis antes vistas, puesto que incluso tras romper con el maleficio de la página en blanco el libro acaba con él. El poema que Chocano escribe antes de enfermar, y del que intenta advertir inútilmente al protagonista en su lecho de muerte, desencadena el final del relato al revelar la verdadera naturaleza del libro:

Contienen todas las penas del mundo

Líbrate de ellos como de una maldición

La de la gitana que desdeñaste en tu infancia

La del amigo que ofendiste un día

Una estatuilla egipcia puede enloquecerte

Un anillo arruinarte

Un libro no escrito conducirte a la muerte (Ribeyro, Palabra 152)

El poema enumera un pequeño listado de objetos mágicos que están encantados y portan «todas las penas del mundo» y en sus versos convergen muchos de los puntos que hemos analizado hasta este momento: la magia, el objeto mágico y el libro asesino. Así, junto al anillo, que nos devuelve a los libros de caballería, y una estatuilla egipcia, un guiño tal vez al «El ídolo de las Cícladas» de Cortázar, el libro en blanco de Ribeyro se ubica por sí mismo como uno más en el imposible museo de lo maligno. Sin embargo, resalta sobre todo el verso «un libro no escrito [puede] conducirte a la muerte», que nos permite volver a la tesis del gran libro ausente, el cual solo llegó a sus manos en la forma de un libro en blanco:

Leyendo hace poco a Cervantes pasó por mí un soplo que no tuve el tiempo de captar (¿por qué?, alguien me interrumpió, sonó el teléfono, no sé), desgraciadamente, pues recuerdo que me sentí impulsado a comenzar algo... Luego, todo se disolvió. Guardamos todos un libro, tal vez, un gran libro, pero que en el tumulto de nuestra vida interior rara vez emerge o tan rápidamente que no tenemos tiempo de arponearlo. (Ribeyro, Tentación 663, 8/12/1978, énfasis mío)

En «El libro en blanco», al inicio del relato, tras recibir el libro de parte de su amiga, el narrador piensa: «Ya me imaginaba escribiendo en esas páginas sentencias o microtextos memorables» (147). Ribeyro se consideraba a sí mismo «un corredor de distancias cortas. Si corro el maratón me expongo a llegar al estadio cuando el público se haya ido» (Dichos, 12). Prosas apátridas, su diario La tentación del fracaso y, en menor medida, Dichos de Luder, dan cuenta de ello. La analogía, pues, es inevitable. Con este relato, Ribeyro parece retomar la búsqueda de esa gran novela desde una perspectiva escéptica, burlándose de sí mismo, pues, como el protagonista, el escritor peruano también vivió en París y trabajó como traductor para la agencia France-Presse de 1961 a 1972. Si bien su estancia allí le permitió un sueldo suficien- 
te para sobrellevar su pobreza parisina, le supuso a la vez tener que robar horas al ejercicio literario, como ha expresado en su diario y sus cartas:

Mucha gente cree que vivo en París "como escritor", consagrado exclusivamente a la creación de una "gran obra" y se extrañan que no publique con mayor frecuencia. Ignoran que soy un miserable empleado a sueldo, que trabajo siete horas diarias en una agencia corrigiendo, traduciendo y redactando cables, y que en los dos años que llevo acá me han lavado toda la poesía de la cabeza y pronto me quitarán toda ilusión. (Ribeyro, Cartas 49)

En tal sentido, a través de la figura del libro en blanco, esa «pieza de artesanía fina -literalmente, una joya destinada a la escritura- y [...] [a la vez] un fetiche de la desgracia» (Elmore 57), Ribeyro no solo da forma a ese «momento de fricción» entre dos realidades yuxtapuestas, sino que a su vez es una forma de saldar una vieja deuda pendiente con el destino.

\section{Conclusiones}

En «El libro en blanco», Ribeyro aborda el tópico del objeto mágico a través de la forma de un libro maldito. Como se ha demostrado, esta clase de libros aparecen en la literatura desde muy temprano, ligados -incluso de manera indisociable- a los libros mágicos. El relato de Ribeyro, sin embargo, renueva este motivo a partir de concebir el objeto como agente de su propia maldad. Así, el uso de la ironía, lo metaliterario y, sobre todo, los guiños autobiográficos, aparecen dispuestos de manera que el hecho fantástico cobra una mayor profundidad.

Se ha buscado presentar que la ausencia de contenido en el libro de Ribeyro no responde, como han podido analizar otros críticos anteriormente, a una intención de hacer fantástico el miedo del escritor a la página en blanco, sino que la figura de un volumen maldito sirve a Ribeyro para, una vez más, reflexionar sobre su destino como escritor, si bien desde una perspectiva más escéptica.

La asociación del libro con el destino, además, resulta inevitable. Es una relación que podemos observar en la escultura de las Moiras de Johann Gottfried Schadow, donde una de ellas aparece leyendo un libro; como también en el cómic The Sandman de Neil Gaiman, donde a la personificación del destino se le ve siempre llevando consigo un libro bajo el brazo en el que está escrito todo lo que fue, es y será.

En suma, «El libro en blanco» se revela como un eslabón más en una larga cadena de asesinos sigilosos. Su singularidad, sin embargo, no solo radica en su capacidad para obrar de manera independiente, sino que, además, en el silencio de sus páginas, se proyectan las sombras de una lucha encarnizada entre un escritor y la gran novela que le fue esquiva.

\section{Obras citadas}

Belevan, Harry. Antología del cuento fantástico peruano. Lima: Editorial Universidad Nacional Mayor de San Marcos, 1977. Impreso. 
Bessière, Irène. «El relato fantástico: forma mixta de caso y adivinanza». Teorías de lo fantástico. De David Roas, ed. Madrid: Arco Libros, 2001. 83-106. Impreso.

Borges, Jorge Luis, Adolfo Bioy Casares y Silvina Ocampo. Antología de la literatura fantástica. Barcelona: Edhasa, 1999. 9-15. Impreso.

Borges, Jorge Luis. Obras completas 1923-1972, Buenos Aires: Emecé Editores, 1974. Impreso.

Calvino, Italo. Mundo escrito y mundo no escrito. Madrid: Siruela, 2006. Impreso. Impreso.

Cortázar, Julio. Historias de cronopios y de famas. Madrid: Punto de lectura, 2013. Impreso.

Elmore, Peter. El perfil de la palabra. La obra de Julio Ramón Ribeyro. Lima: Fondo Editorial de la Pontificia Universidad Católica del Perú, 2002. Impreso.

Esteban, Ángel, ed. Cuentos: Antología. De Julio Ramón Ribeyro. Madrid: Espasa-Calpe, 1998. Impreso.

González Montes, Antonio. «El mundo de la literatura en Sólo para fumadores de Julio Ramón Ribeyro». Tesis. Universidad Nacional Mayor de San Marcos, 2010. Página web. 11 en. 2018. http://cybertesis.unmsm.edu.pe/bitstream/cybertesis/1348/1/Gonzalez_ma.pdf.

Higgins, James. «Un sereno escepticismo». Cambio social y constantes humanas: la narrativa corta de Ribeyro. Lima: Pontificia Universidad Católica del Perú, 1991. 153-171. Impreso.

Martínez, José María. «Los cuentos fantásticos de Julio Ramón Ribeyro: taxonomías y recepción». Revista de Crítica Literaria Latinoamericana XXXIV, 67 (2008): 255-272. Impreso.

- «Fantasías irónicas e ironías fantástica: sobre Amado Nervo y el lenguaje modernista». Hispanic Review 72, 3 (2004): 401-421. Impreso.

- «Subversión u oxímoron: la literatura fantástica y la metafísica del objeto». Rilce 26, 2 (2010): 363-382. Impreso.

Minardi, Giovanna. «La dimensión fantástica». La cuentística de Julio Ramón Ribeyro. Lima: Pontificia Universidad Católica del Perú, 2001. 67-93. Impreso.

Mountfort, 2016. «The I Ching and Philip K. Dick's The Man in the High Castle». ScienceFiction Studies 43, 2 (2016): 286-309. Página web. 24 en. 2018. https://www.researchgate.net/publication/304007667_The_I_Ching_and_Philip_K_Dick's_The_Man_in_the High_Castle.

Nasif, Mónica. «Los objetos mágicos en los libros de caballerías españoles: una posible clasificación». Literatura medieval y renacentista en España: líneas y pautas. De Natalia Fernández Rodríguez y María Fernández Ferreiro, eds. Salamanca: Sociedad de Estudios Medievales y Renacentistas, 2012. 775-781. Página web. 19 en. 2018. http://repositoriodigital-la-semyr.es/index.php/rd-ls/catalog/view/51/45/1320-1.

Roas, David. Tras los límites de lo real. Una definición de lo fantástico. Madrid: Páginas de Espuma, 2011. Impreso.

Roas, David, Natalia Álvarez y Patricia García. «Narrativa 1980-2015». Historia de lo fantástico en la cultura española contemporánea (1900-2015). De David Roas, dir. Madrid: Iberoamericana, 2017. 195-214. Impreso.

Rodero, Jesús. «Un inventario de enigmas. Los cuentos fantásticos de Julio Ramón Ribeyro». Ínsula 826 (2015): 22-25. Impreso.

Rodríguez Pequeño, Javier. «Referencia fantástica y literatura de transgresión». Tropelías 2 (1991): 145-156. Impreso.

Rodríguez Monegal, Emir. «Jorge Luis Borges y la literatura fantástica». Número 1, 5 (1949): 448-454. Página web. 28 en. 2018. https://es.scribd.com/document/365396731/JorgeLuis-Borges-y-La-Literatura-Fantastica. 
Ribeyro, Julio Ramón. Cartas a Luchting 1960-1993. Ed. Juan José Barrientos. Xalapa: Universidad Veracruzana, 2016. Impreso.

- Dichos de Luder. Lima: Lápix Editores, 2014. Impreso.

- La palabra del mudo, Seix Barral, Barcelona, 2010. Impreso.

- Las respuestas del mudo. Ed. Jorge Coaguila. Lima: Revuelta Editores, 2015. Impreso.

- La tentación del fracaso, Seix Barral, Barcelona, 2003. Impreso.

Thompson, Stith. Motif-Index of Folk-Literature. Bloomington: Indiana University Press, 1966. Impreso.

Thorpe, Benjamin. Northern Mythology, Comprising the Principal Popular Traditions and Superstitions of Scandinavia, North Germany, and the Netherlands. Londres: Edward Lumley, 1851. Página web. 27 en. 2018. https://ia800200.us.archive.org/18/items/northernmytholog02thor/northernmytholog02thor.pdf.

Todorov, Tzvetan. «Lo extraño y lo maravilloso». Teorías de lo fantástico. De David Roas, ed. Madrid: Arco Libros, 2001. 65-81. Impreso.

Vandoorne, Pierre. «Bibliotecas y voces imposibles: dos casos fantásticos en la literatura peruana del siglo XX». Tesis. Pontificia Universidad Católica del Perú, 2011. Página web. 21 en. 2018. http://tesis.pucp.edu.pe/repositorio/handle/123456789/7774.

Vargas Llosa, Mario. «Ribeyro y las sirenas». Asedios a Julio Ramón Ribeyro. De Ismael P. Márquez y César Ferreira, eds. Lima: Fondo Editorial de la Pontificia Universidad Católica del Perú, 1996. 261-264. Impreso.

Vidal, Luis Fernando. «Ribeyro y los espejos repetidos». Revista de Crítica Literaria Latinoamericana 1 (1975): 73-88. Impreso.

Weitzdörfer, Ewald. «Lo fantástico en los cuentos de Julio R. Ribeyro». Alpha 26 (2008): 193-202. Página web. 13 en. 2018. https://dialnet.unirioja.es/descarga/articulo/2695267. pdf. 